\title{
Three-dimensional gravity modeling of Chicxulub Crater structure, constrained with marine seismic data and land boreholes
}

\author{
José A. Batista-Rodríguez ${ }^{1}$, Marco A. Pérez-Flores ${ }^{2}$, and Jaime Urrutia-Fucugauchi ${ }^{3}$ \\ ${ }^{1}$ College of Engineering, Universidad Autónoma de Coahuila, Blvd. Adolfo López Mateos S/N, \\ Nueva Rosita, Coahuila, México \\ ${ }^{2}$ Department of Geophysics, Centro de Investigación Científica y de Educación Superior de Ensenada Baja California-CICESE, \\ Baja California, México \\ ${ }^{3}$ Programa Universitario de Perforaciones en Océanos y Continentes, Instituto de Geofísica, Universidad Nacional Autónoma de México, \\ México, Coyoacan 04510 México D.F., México
}

(Received August 15, 2012; Revised April 22, 2013; Accepted May 28, 2013; Online published October 9, 2013)

\begin{abstract}
We present a three-dimensional multi-formation inversion model for the gravity anomaly over Chicxulub Crater, constrained with available marine seismic data and land boreholes. We used eight formations or rock units as initial model, corresponding to: sea water, Paleogene sediments, suevitic and bunte breccias, melt, Cretaceous carbonates and upper and lower crust. The model response fits $91.5 \%$ of the gravity data. Bottom topography and thickness plots for every formation are shown, as well as vertical cross-sections for the 3-D model. The resulting 3-D model shows slightly circular features at crater bottom topography, which are more prominent at the base of the breccias unit. These features are interpreted as normal faults oriented towards the crater center, revealing a circular graben-like structure, whose gravity response correlates with the rings observed in the horizontal gravity gradient. At the center of the model is the central uplift of upper and lower crust, with the top covered by an irregular melt layer. Top of the upper crust shows two protuberances that can be correlated with the two positive peaks of the gravity anomaly. Top of Cretaceous seems to influence most of the response to the gravity anomaly, associated with a high density contrast.
\end{abstract}

Key words: Three-dimensional inversion, gravity anomaly, Chicxulub Crater.

\section{Introduction}

Chicxulub is considered the best preserved example of a large terrestrial multi-ring basin crater (Fig. 1). The crater was buried by Paleogene sediments after the impact and has not been exposed to degradation by erosion and weathering, or affected by tectonic and volcanic processes. The Chicxulub Crater has been related to the asteroid impact at 65.5 Ma, at the boundary between the Cretaceous and the Paleogene (Hildebrand et al., 1991; Sharpton et al., 1992; Schulte et al., 2010; Urrutia-Fucugauchi et al., 2011). The shock wave crashed/melted the target Mesozoic and upper crustal rocks. The excavation cavity reached a depth of about $25 \mathrm{~km}$, affecting most of the crust. Because of the energy delivered at the crust, it is suggested that a rebound of the lower crust was produced, affecting the crust-mantle boundary and producing the central basement uplift. Immediately after crater formation, it was filled by fragmented debris with emplacement of the bunte and suevitic breccias formations. Slowly afterwards, the structure was buried and covered by marine carbonate sediments.

To investigate on the impact and cratering processes, it is necessary to get a detailed knowledge of the geometric characteristics of the crater and crater stratigraphy. In the

Copyright (C) The Society of Geomagnetism and Earth, Planetary and Space Sciences (SGEPSS); The Seismological Society of Japan; The Volcanological Society of Japan; The Geodetic Society of Japan; The Japanese Society for Planetary Sciences; TERRAPUB.

doi: $10.5047 /$ eps.2013.05.015 past three decades several geological and geophysical studies have been completed at Chicxulub, which provide useful information about puzzling pieces for the impact event and crater formation.

In this paper, we present a three-dimensional (3-D) density model of the Chicxulub Crater (inside the outer ring) obtained from modeling the Bouguer gravity anomaly, and constraining the solutions with marine seismic data and borehole information (Fig. 1). We aim to obtain a high resolution model for the crater that incorporates the major structural elements. We also uncover new characteristics for the crater geometry, on the dimensions and form of the central uplift, circular fault systems and three-dimensional mass distribution of formations.

\section{Method}

The gravity anomaly field over Chicxulub impact crater is shown in Fig. 2. Low gravity anomaly values form a ring with an extension towards the NW. When applying horizontal derivatives to this anomaly, several rings become apparent in the anomaly pattern, which enhance the high horizontal gravity gradient (Sharpton et al., 1993; Pilkington et al., 1994; Hildebrand et al., 1998).

To derive the three-dimensional density model from the Bouguer gravity anomaly we used the software developed by Gallardo et al. (2005). Basically, it determines the top and bottom depths for multiple rectangular prisms using inequality or equality constraints for those depths. We assume 


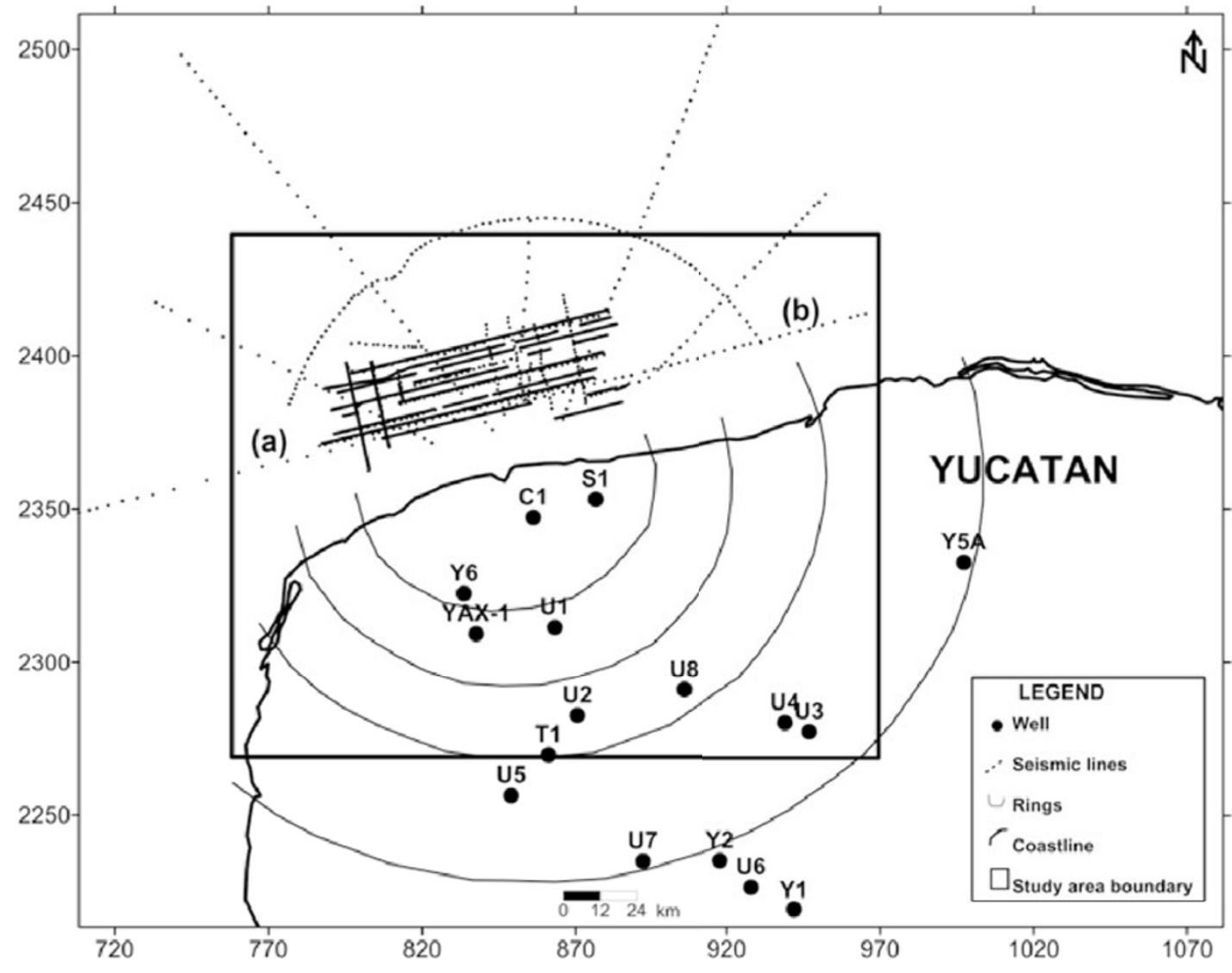

Fig. 1. Inner box shows the study area. Irregular line indicates the Yucatan coastline. Dotted lines point out the seismic lines locations. Thick dots are land borehole. Circular lines are rings obtained from the first horizontal derivate of the gravity field.

that the subsurface consists of formations with irregular bottom and top topography in contact with other formations. We simulate every formation with a conglomerate of rectangular prisms as shown in Fig. 2 (prisms from 1 to 320). Every formation is constituted of a separate set of prisms with different density contrasts. In Fig. 3 we show a vertical cross-section of four formations and their respective set of prisms. We assume a constant horizontal cross-section area for all the prisms. That geometrical arrangement is useful for locating which prisms are placed at the sides, over or under. The inversion process moves the top and bottom topography for every single prism at every formation. Restrictions are imposed to not allow overlapping or spaces between prisms. We try to minimize the quadratic norm of the differences between data $\left(\mathbf{g}_{o}\right)$ and model response $\left(\mathbf{g}_{r}\right)$ plus a term of smoothing (Eq. (1)).

$$
F(\mathbf{m})=\left\|\mathbf{g}_{o}-\mathbf{g}_{r}\right\|^{2}+\beta\|\mathbf{D m}\|^{2},
$$

subject to

$$
\mathbf{m}_{\text {low }} \leq \mathbf{m} \leq \mathbf{m}_{\text {upper }},
$$

where $\mathbf{m}$ is the unknown vector containing the depths from every prism. Matrix $\mathbf{D}$, are the horizontal $(x, y)$ first derivatives of the depths. This term tries to minimize the bottom depth differences between adjacent prisms. Term $\beta$ magnifies or dismiss this term. When it is zero the model shows very rough top topography for every formation; when large, every formation topography is smooth, except where the data (first term in Eq. (1)) requires larger jumps. This could happen where the geological faults are located and influence the geometric arrangement. We use smooth threedimensional models, considering that the simplest model is more probable (Occam's razor rule). Thus, the resulting models show lower depth gradients and angle faults become smaller than real dip angles.

Depth determination can be quoted by mean of quadratic programming (Gill et al., 1986). We can use inequalities or equalities. In this way, it is possible to introduce surface geology, wells and seismic data as constraints. This will allow to optimize the inversion process, and to do not change the surface geology and thickness introduced in some prisms, constrained from seismic and well data.

Surface geology can be introduced as a priori information (as constrains in the model). From Fig. 3 we can observe that formation-1 prisms are displaced to allow formation2 prisms outcropping. This is made in the algorithm by collapsing the formation-1 prisms thickness to zero. This can happen on the surface or the subsurface. Topography for the Paleogene sedimentary unit was introduced this way. This unit is observed everywhere except where the sea unit is present.

For the modeling, the horizontal prism area was fixed in $10 \mathrm{~km} \times 10 \mathrm{~km}$ as shown in Fig. 2, giving a set of 320 prisms for every rock formation. In Table 1 the eight main rock groups are listed, which are considered for the inversion process. The inversion process will relocate the bottom 


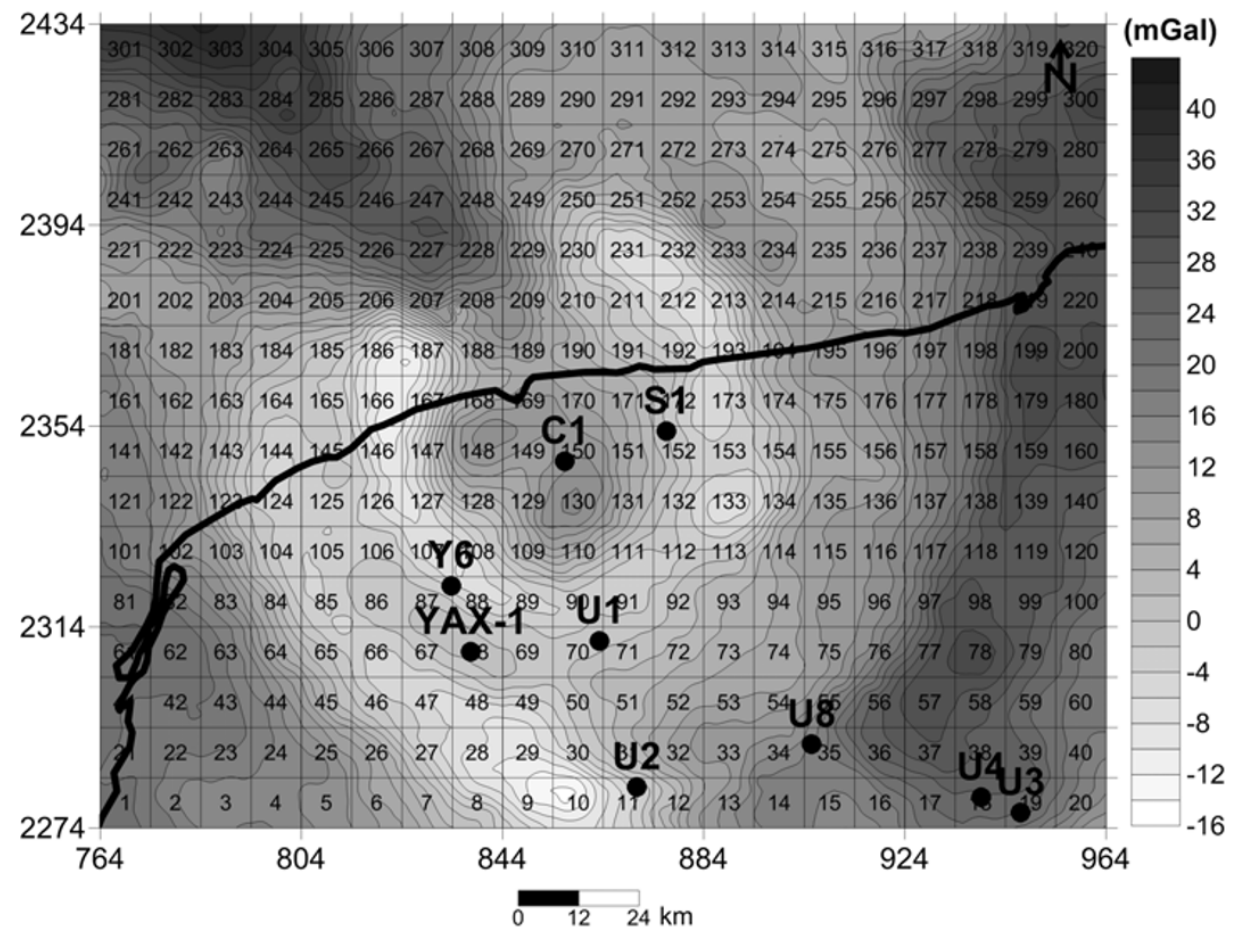

Fig. 2. Schematic gravity anomaly field over Chicxulub impact crater. Black dots represent location of exploratory wells.

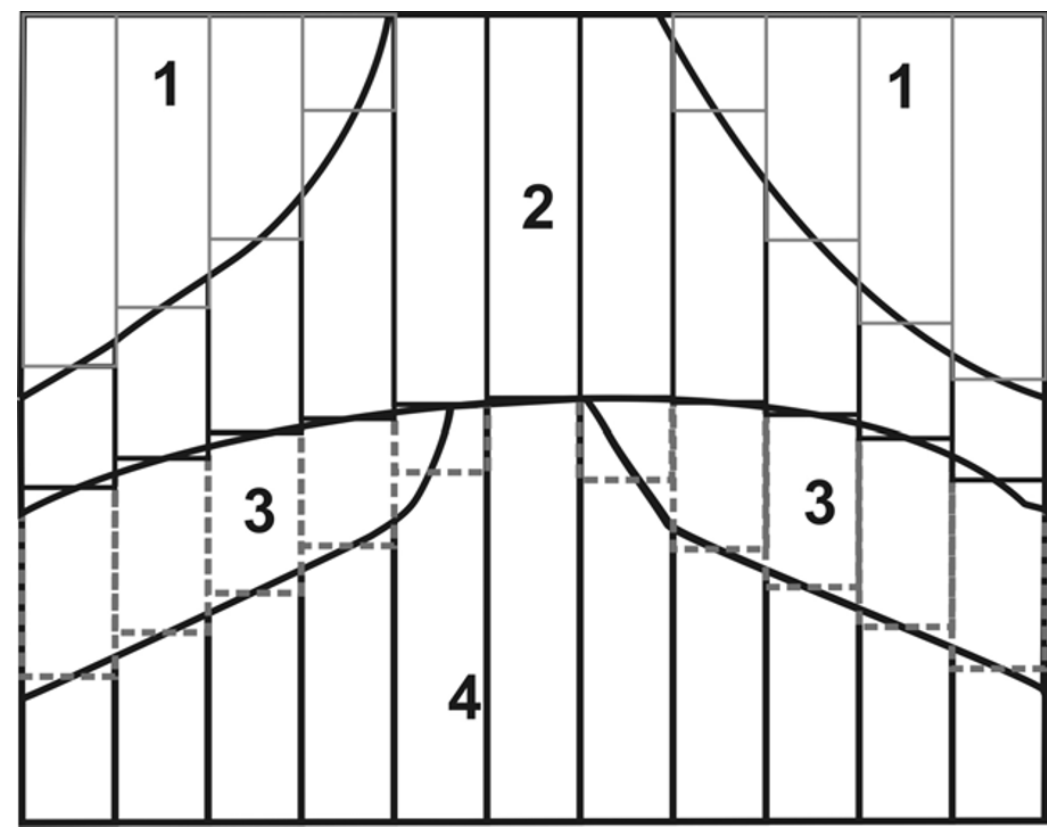

Fig. 3. Example of prismatic ensembles for four geological formations.

depth for every single prism of every formation. Densities are considered as known variables. Therefore it is necessary to have an adequate estimation for the densities of the formations.

Data on physical properties have been reported from analyses on samples from borehole cores (e.g., Sharpton et al., 1996; Urrutia-Fucugauchi et al., 1996; Vermeesch and Morgan, 2004; Mayr et al., 2008; Elbra and Pesonen, 2011). Data are however limited to the upper formations of the carbonate sequences and breccias, which have been sampled in the boreholes.
In Table 1 we list the densities considered for our best model, but we also show the density range given in previous studies. Breccias formation for the first approximation was considered as a homogeneous layer, which resulted in a relatively poor fit over the low gravity values. Morgan et al. (2000) reported low seismic velocities, which may indicate an area of low densities that could be linked to highly fractured rocks. Therefore we decided to split the breccias formation into two units: bunte and suevites, which associated different density contrasts. Low velocity requires low density. Inclusion of bunte breccias allows our 3-D model 
Table 1. List of formations considered for the inverse process. Density values for the different units and corresponding references.

\begin{tabular}{|l|l|c|}
\hline Layer & \multicolumn{1}{|c|}{ Lithology } & $\begin{array}{c}\text { Density } \\
\left(\mathbf{g} / \mathbf{c m}^{\mathbf{3}} \mathbf{)}\right.\end{array}$ \\
\hline 1 & Sea & 1.03 \\
\hline 2 & Paleogene rocks & 2.67 \\
\hline 3 & Suevitic breccias & 2.55 \\
\hline 4 & Bunte breccias & 2.0 \\
\hline 5 & Impact Melt rocks & 2.56 \\
\hline 6 & Cretaceous Carbonate & 2.65 \\
\hline 7 & Upper crust & 2.67 \\
\hline 8 & Lower crust & 2.70 \\
\hline
\end{tabular}

to fit better the lowest gravity anomaly values. However, we use the same color for representing both. The Impact melt formation was introduced even though its gravity response is very small, mainly because it is a thin layer. A formation representing the mantle was considered in our first trials. The anomaly is constrained between -16 and 40 mgal. If we considered the mantle, the anomaly would range around a hundred mgal. We assume that the anomaly has no information of the mantle.

Marine seismic data reported by Gulick et al. (2008) and land boreholes (Urrutia-Fucugauchi et al., 1996, 2004, 2008) plotted in Fig. 1 were used as constraints. From the seismic sections by Gulick et al. (2008), it was possible to extract the bottom depth for the Paleogene. We also derived the bottom depths for the breccias, with some uncertainty associated with identification of the reflectors. The bottom of the Quaternary sediments is almost hidden, but we could at least get an average depth. With this information we manipulated the constraints for every prism affected (Figs. 1 and 2). We gave a 5\% variation for the seismic constraints. Assuming that Chicxulub is characterized by circular symmetry we derived similar constraints at its mirror inland sector, but assuming a variation of $20 \%$. For the information from the exploratory wells it was a little different. The prisms have an area of $10 \mathrm{~km} \times 10 \mathrm{~km}$ and the wells are less than $0.5 \mathrm{~m}^{2}$ (a needle). The depth reported in the well cannot be representative of the whole prism area. At first, we tried with reduced variations and we did not reached convergence. Then, we assumed a $10 \%$ variation for the constraints and the convergence improved. Working with constraints is not easy. Using many constraints since the beginning in general the inversion process works like a straitjacket avoiding the convergence of the iterative process. Therefore, we first ran our models without any constraints, then added obvious constraints like the bottom depth for the Paleogene, then depths for the breccias formations and lastly the borehole information. This results in a long trial and error process, even though 3-D inversion algorithm is fast.

\section{Comparison Between Data and Response}

Density is considered as known and obtained from field samples or previous works. Density contrast is considered constant for the whole set of prism constituting one formation. This simplification results in tedious work, because we have to explore dozens of combinations, even when a formation density contrast has a relatively narrow variation range. Field-sampling densities can be slightly different from the bulk density needed by the algorithm. The inverse process is non-linear, and we arrive to the solution iteratively. When the density combinations are not optimal the inversion process does not reach convergence or the misfit is large. We made dozens of combinations in order to have convergence and to get the lowest misfit. The final or bestfitting model was obtained with a $91.5 \%$ misfit. The gravity response (Fig. 4(b)) of the best model is very similar to the observed data (Fig. 4(a)) and the difference between them is mainly random (Fig. 4(c)). We selected three profiles to evaluate the fitness degree.

\section{Results and Discussion \\ 4.1 Central uplift}

Maybe the most intriguing feature is the central uplift caused by the rebound of the upper, lower crust and possible the mantle when the pre-existed Cretaceous rock were crashed and/or melted by the shock wave. This central uplift has been reported in previous modeling studies, with contrasting sizes and shape (e.g., Morgan et al., 1997; Hildebrand et al., 1998; Morgan and Warner, 1999; Christeson et al., 2001; Campos-Enríquez et al., 2004; Vermeesch and Morgan, 2004, 2008; Ortiz-Alemán and Urrutia-Fucugauchi, 2010). Land boreholes located near the impact center, reached the upper part of the impact melt unit (Rebolledo-Vieyra et al., 2000) but they did not crossed it, getting a very broad delineation of the distribution of the unit. They recognized that a melt layer is present, distributed close to the crater center. So the thickness, extension and geometry of the melt formation remain unknown. The possible response of twin peak on the top of the central uplift can be observed in the shape of gravity anomaly (see Figs. 4(a), 4(d), profile 11). You can observe those features in our 3-D model. But, we first will show the bottom topography for every formation and then discuss the details mentioned above.

The 3-D model consists of eight formations and seven interfaces or topographies between them. In Fig. 5 we show the bottom topography for the five formations considered unknown (excluding; Top topography-bathymetry of the Paleogene and suevites bottom topography). We draw the gravity rings in order to find some radial behavior only. Even that resolution is low $(10 \mathrm{~km} \times 10 \mathrm{~km}$ prisms were used), the Paleogene bottom topography shows some radial patterns as shown on large multi-ring basin craters on the moon. This topography was constrained by marine seismic (Fig. 1) in order to reduce non-uniqueness. This radial behavior looks more obvious at the bottom of the breccias.

Using information from land boreholes, we assumed the 

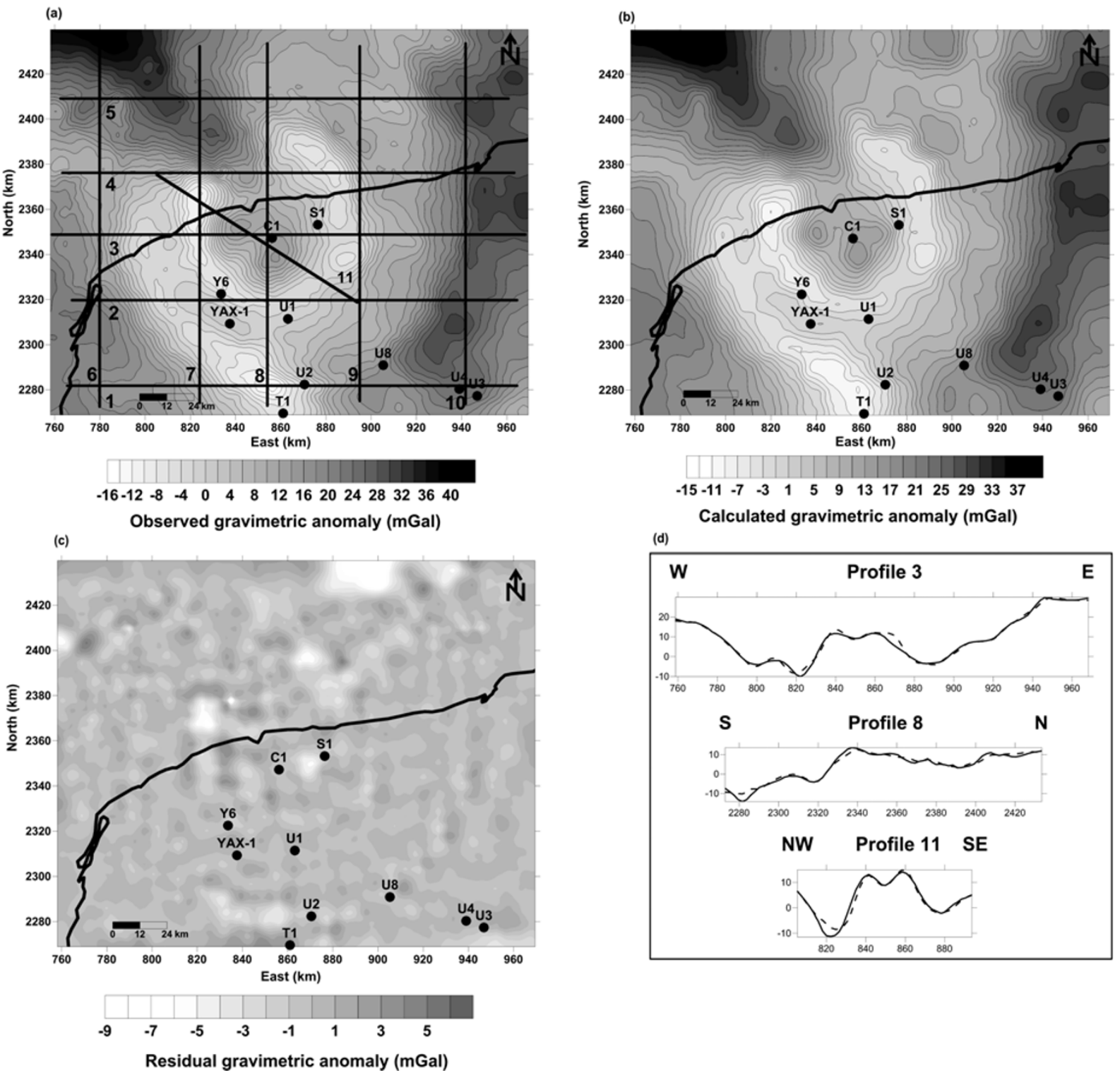

Fig. 4. (a) Bouguer gravity data, lines represents profiles over which we did cross-sections of the 3-D model. (b) Response of the best model (96\% fitness). (c) Difference between data and response. (d) Three profiles over the data (solid line) and their responses (dotted line).

presence in the model of a thin breccias layer (suevites) at the impact center and also an impact melt sheet (RebolledoVieyra et al., 2000). Breccias formation could be thicker at the whole crater except the center, but melt seems to be confined at center, where the highest temperatures were reached by the impact. No Cretaceous units are present proximally. This makes sense because the impact fragmented and melted the Cretaceous layer close to the center. Figure 5(b) shows presence of the central uplift. Bottom topography of the melt differs from the breccias topography slightly at the center. Here we can observe that there is some topography relief under the melt (Fig. 5(c)). The upper crust lies below the melt. As we will see in a later section that upper crust shows two protuberances at the top of the central uplift. The upper and lower crust lies below the Cretaceous. We note that the top of upper crust at the central uplift lies at around $2 \mathrm{~km}$ and the top of the lower crust at around $4 \mathrm{~km}$. These are similar to those in models by other authors (Pilkington and Hildebrand, 2000; Salguero-Hernández et al.,
2010). Outside the central uplift, Cretaceous layer is below the breccias. We found relief color plots more informative than plain contours, but two-dimensional cross-sections of the 3-D model are even more informative as we will see.

Cross-sections were done W-E $(1,2,3,4,5)$ and S-N $(6,7,8,9,10)$ as seen on Fig. 4(a). Cross-sections 3 and 8 (Fig. 6) show details of the central uplift structure. The analysis indicates that the top of the central uplift is not flat. Our 3-D model shows that the upper crust rebound produces two protuberances at the central uplift in both W-E and S$\mathrm{N}$ directions. Those gravity protuberances cannot produced by melt, because is less dense than the lower crust. Over these protuberances is the melt layer. The top topography of the melt layer is irregular in the W-E direction and almost flat in the S-N. Gravity anomaly is less sensible to the melt layer, but magnetic anomaly must be more sensible. Also, those two protuberances at the gravity anomaly looks like a low frequency anomaly and they can only be justified with two protuberances in the upper and lower crust (at 2 and 5 


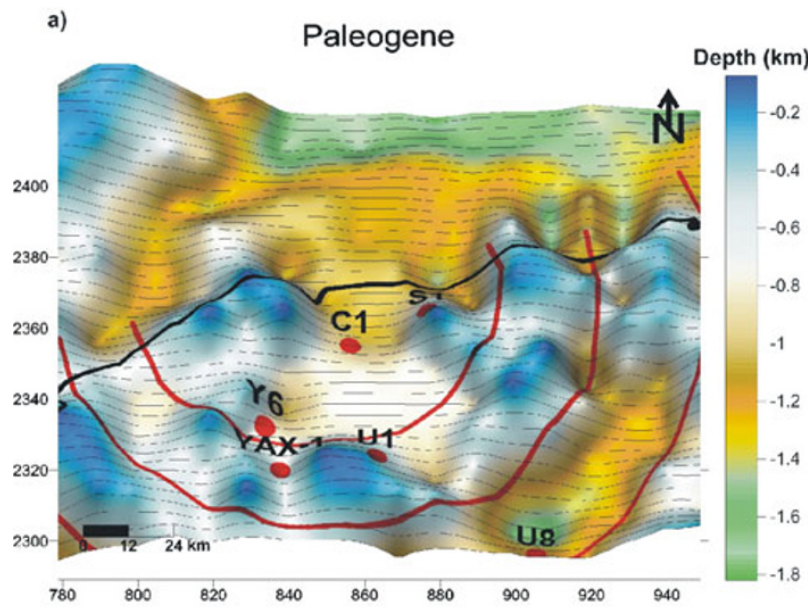

c)
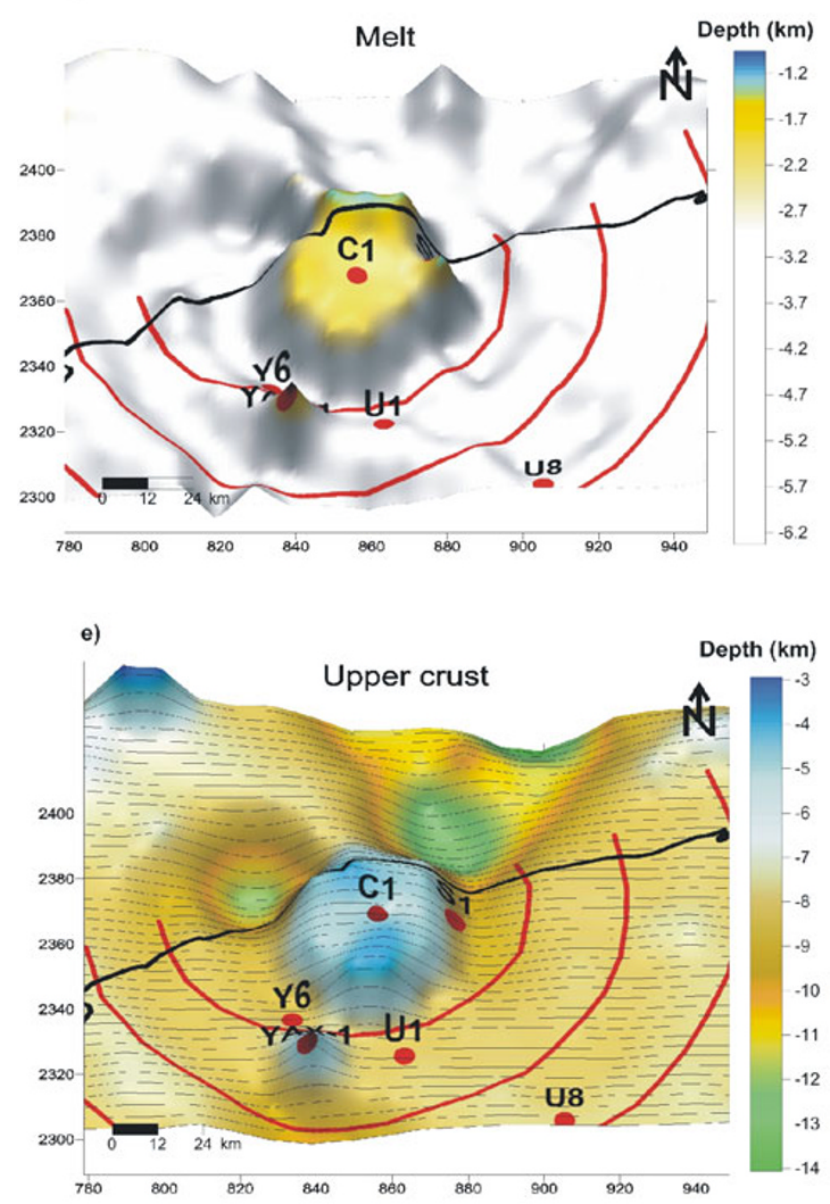

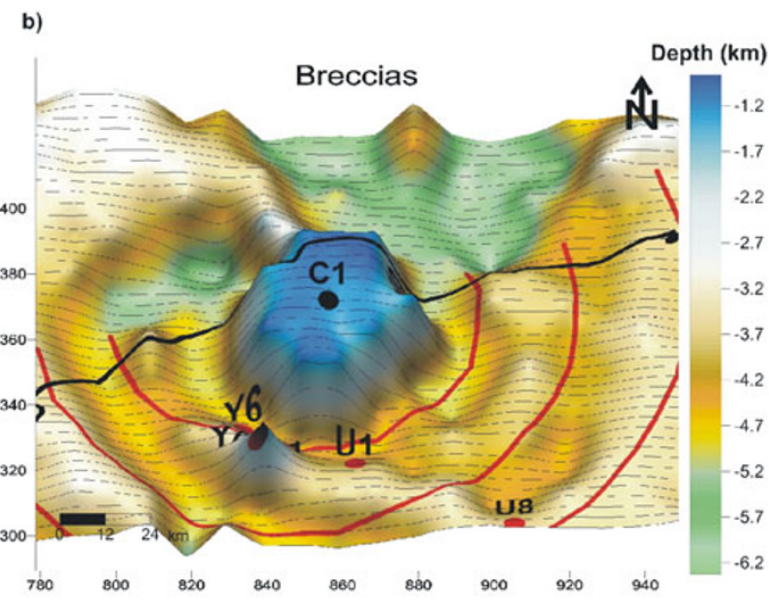

d)

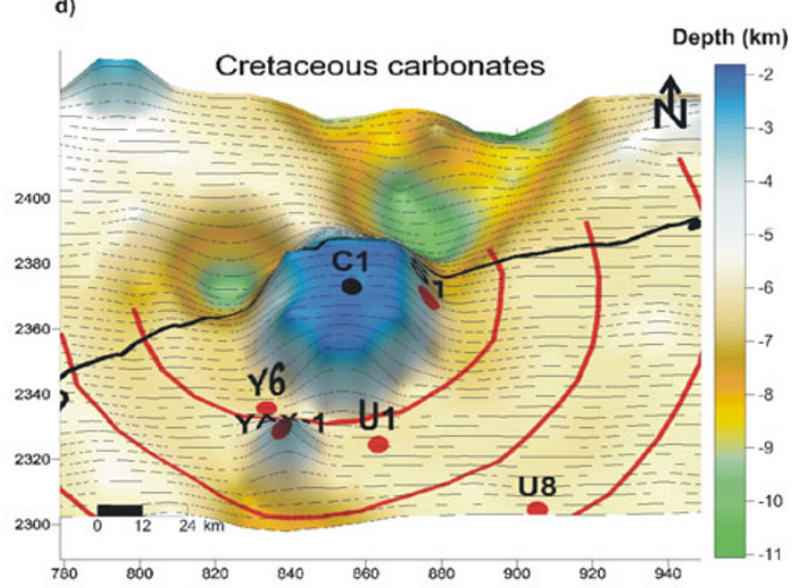

Fig. 5. Depths of rock groups: a) Paleogene; b) Breccias; c) Melt; d) Cretaceous carbonates; e) Upper crust. Red points are exploratory wells and the circular lines are rings, both shown in Fig. 1.

$\mathrm{km}$ depth respectively), instead of the melt layer.

From our cross-sections, the central uplift appears largely responsible for the positive gravity anomaly at the center (Fig. 2), because upper and lower crust are denser than upper formations.

\subsection{Multi-rings}

Figure 5(a) shows the Paleogene bottom topography determined by 3-D inversion. We must remember that this layer was best constrained at the marine area by mean of the marine seismic. At land area we proposed a mirror as an initial model. But model was wide open to converge at any depth topography. We can find some circular features. aligned with the ring obtained from the horizontal derivative of the gravity anomaly. These circular behavior is very strong at the bottom of the breccias, that also corresponds with the top of the Cretaceous. At this 3D surface the correlation between these circular topographic features and the horizontal gravity gradient rings is very close 

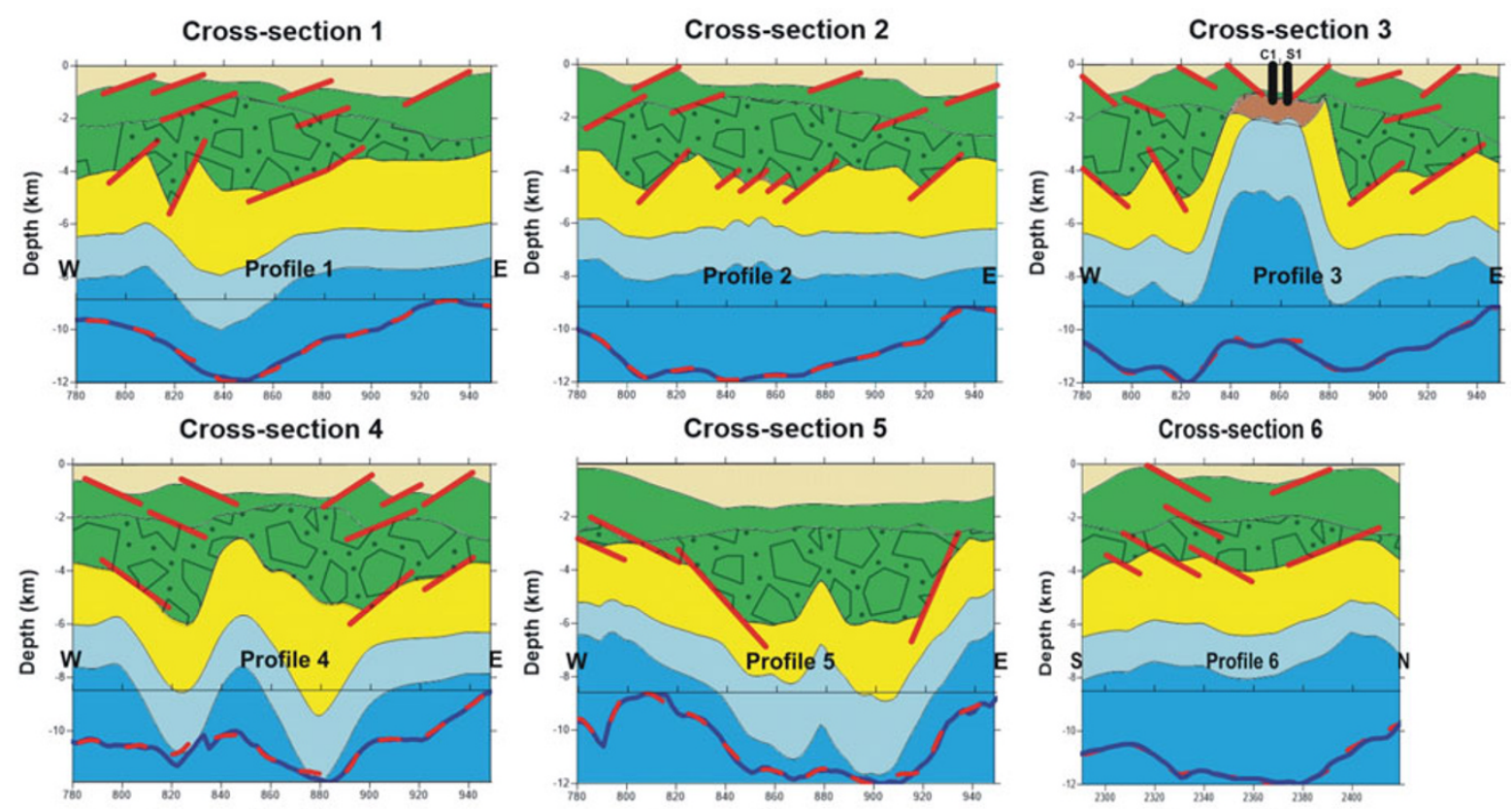

Cross-section 7
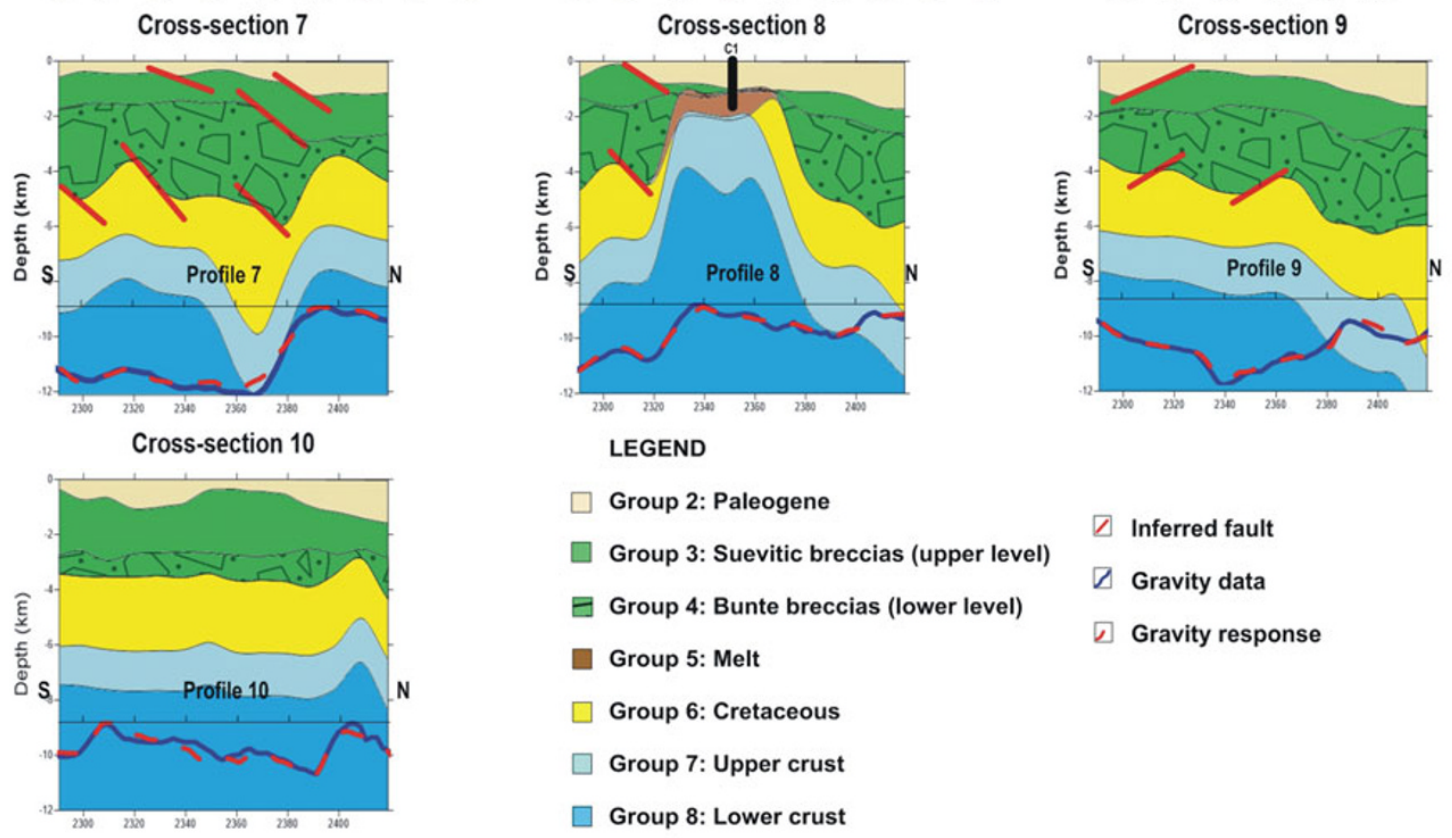

LEGEND

Group 2: Paleogene

Group 3: Suevitic breccias (upper level)

Group 4: Bunte breccias (lower level)

Group 5: Melt

Group 6: Cretaceous

Group 7: Upper crust

Group 8: Lower crust

Fig. 6. Cross-sections obtained from the 3-D model (according the profiles showed in Fig. 4(a)). At each bottom of the section is show the comparison between observed and calculated gravity data.

(Fig. 5(b). According to Sharpton et al. (1993) the gravity gradient rings are located at: ring- 1 at $52 \pm 5 \mathrm{~km}$ from the center, ring-2 at $77 \pm 6 \mathrm{~km}$. Taking the center in section 3 at $x=858$, the ring- 1 must be at $x(806,910)$ and ring-2 at $(781,935)$. These coordinates correspond very well with the top topography highs on the Cretaceous formation. The abrupt change of slope in the top of this layer are producing the high horizontal gradients seen on the gravity anomaly. Applying the same for cross-section 8 (S-N), ring-1 correlates very well with an slope change southward in top Cretaceous, but an small slope change Northward. ring-2 is out of the area in the N-S direction.

The abrupt change of slopes can be attributed to normal faulting as we draw on cross-sections. The trace of this faults is circular, describing a circular graben. These circular fault structures confirm the process of fracturing and collapse of the crater early described by Melosh (1989) and reported in the Chicxulub Crater in several studies (e.g. Sharpton et al., 1993; Morgan et al., 1997, 1999; SalgueroHernández et al., 2010).

Cross-sections (Fig. 6) delineate a pattern of normal faulting towards the center of every section in the way of a circular depression. This is best seen in cross-sections 3 and 8 , passing through the center of the structure. The 3 $\mathrm{D}$ isometric diagrams give a better idea of the shape of the circular depression (Fig. 7). At Cretaceous, the faults observed in isometric diagram can be traced to the other side (90 degrees) showing its continuity (Fig. 7). 

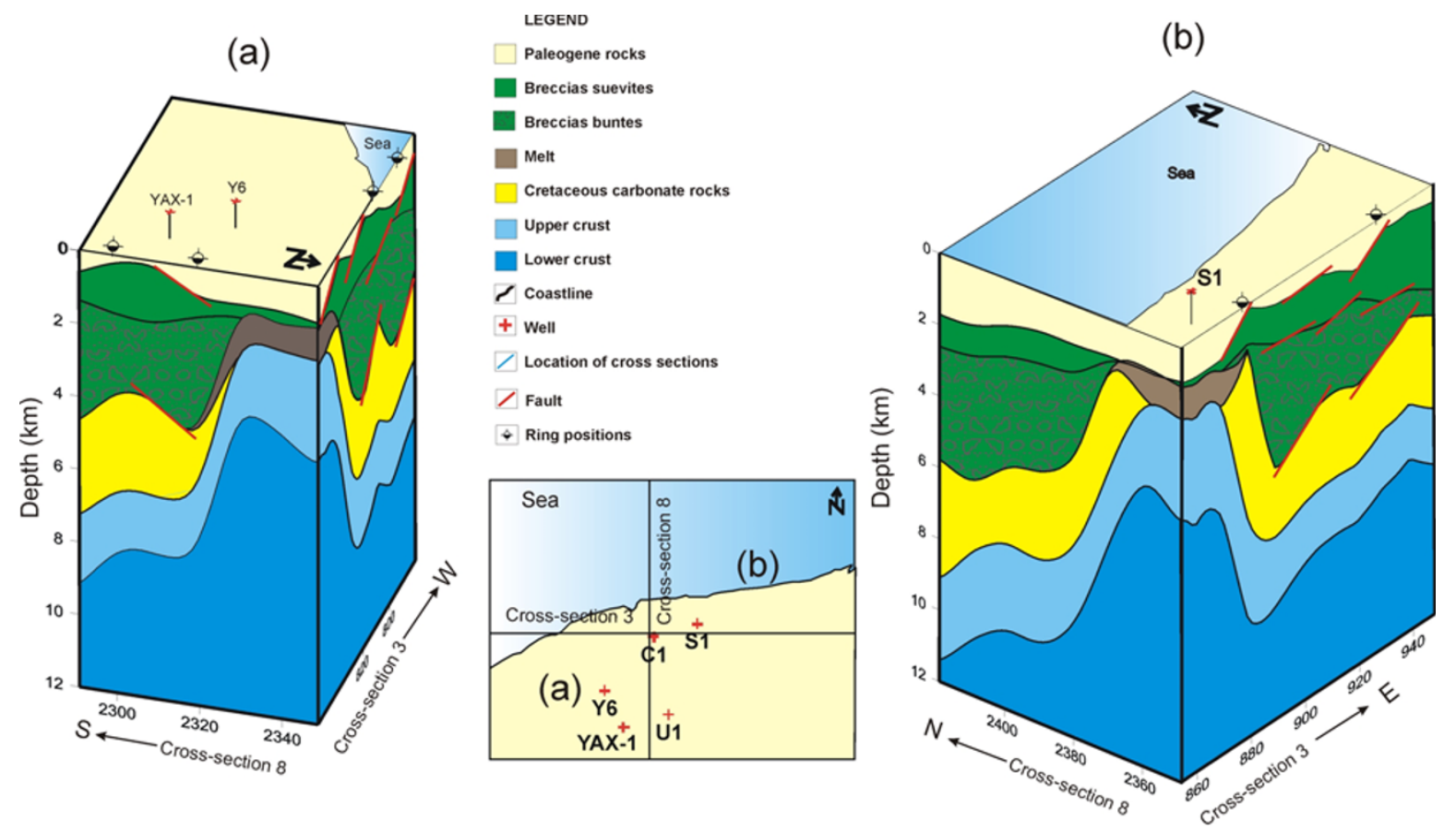

Fig. 7. 3-D isometric diagrams of the quadrant (a) and quadrant (b) of the Chicxulub Crater.

\subsection{Depth variation and thickness}

Figure 5(a) shows the Paleogene bottom topography. Top topography is not plotted, but in-land we assumed a flat terrain of $30 \mathrm{~m}$ over sea level. At marine area we assumed a bathymetry corresponding with a ramp dipping smoothly northward. Bottom Paleogene deeps until $1.8 \mathrm{~km}$ at the $\mathrm{N}$ and $1.6 \mathrm{~km}$ at the SE in a small area close to the center. The shallowest areas $(\sim 200 \mathrm{~m})$ are located at NW, SW and several areas close to the crater center. From the 2-D seismic interpretations, Salguero-Hernández et al. (2010) proposed a range between 0.8 and $1.1 \mathrm{~km}$ for this basin. Our 3-D model parameters agree with that range. Thickness onshore is around $1 \mathrm{~km}$ (Fig. 6), getting thicker offshore $(\sim 2 \mathrm{~km})$ as shown by Sharpton et al. (1996) and in the marine seismic models of Collins et al. (2008).

The bottom relief of the breccias deepens until 6-6.2 km around the central uplift (Fig. 5(b)), meaning that lower values at the gravity anomaly are related with the deepest part of the bottom topography that also corresponds with the larger breccias thickness ( 4 km; Fig. 8(a)). Shallowest values are at the center where the thickness is a minimum $(\sim 150 \mathrm{~m}$; Fig. 8(a)). The bottom depth for these formations was obtained from the inverse process, but controlled by the borehole data and by the marine seismic at the seismic lines extremes.

A melt layer is observed only at the center (Fig. 5(c)), over the central uplift (upper and lower crust) and below the thin breccias formation. Topography of top of this layer is irregular (Figs. 6 and 7), and mainly controlled by the borehole information. The rest of the bottom topography is inferred by the inversion process. Maximum thickness estimated was $1.1 \mathrm{~km}$ (Fig. 8(b)). We consider that the gravity anomaly provides little information about this thin layer.
Cretaceous carbonates are distributed all over the crater, except the central uplift area. The top depth to the Cretaceous is $6.3 \mathrm{~km}$ at the NW and $\mathrm{N}$ of the central uplift or the $4.6 \mathrm{~km}$ around this. This behavior observed around the central uplift, implying that sinking may have occurred close to this structure (Fig. 5(b)). Average thickness is close to $5 \mathrm{~km}$.

Upper and lower crust were needed to model the central uplift, but outside, we have no constraints for those. The top depth to the upper crust is $\sim 2 \mathrm{~km}$ and $\sim 4 \mathrm{~km}$ for the lower crust as shown in the cross-sections (Fig. 6). Due to the lack of constraint outside the central uplift both topography depths are highly correlated, they run almost parallel between them.

Considering the high density contrast between the breccias and Cretaceous sediments, we propose that outside the central uplift the gravity is highly related with the Cretaceous top topography relief. When deepening, gravity anomaly is reduced, while when rising, gravity anomaly values increase. These can be seen graphically at every cross-section and its corresponding gravity profile plotted below each section (Fig. 6).

Cross-section 3 (Fig. 6) and the isometric representation of the base of the Paleogene basin (Fig. 7) do not reach the crater borders. We can only say that diameter must be larger than $140 \mathrm{~km}$.

Error bars for the depth estimation of every topographic surface on the 3D model are discussed on Appendix A.

\section{Conclusions}

We present a new 3-D model of the Chicxulub Crater from the gravity data inversion, constrained by marine seismic and land boreholes. This model is consistent with previous geophysical models. Top of breccias and Cretaceous 
(a)

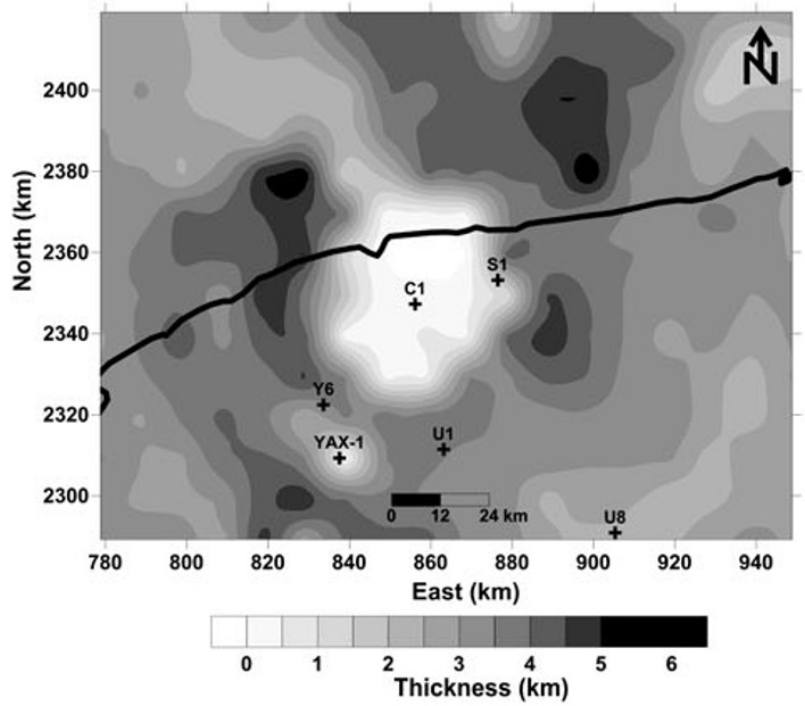

(c)

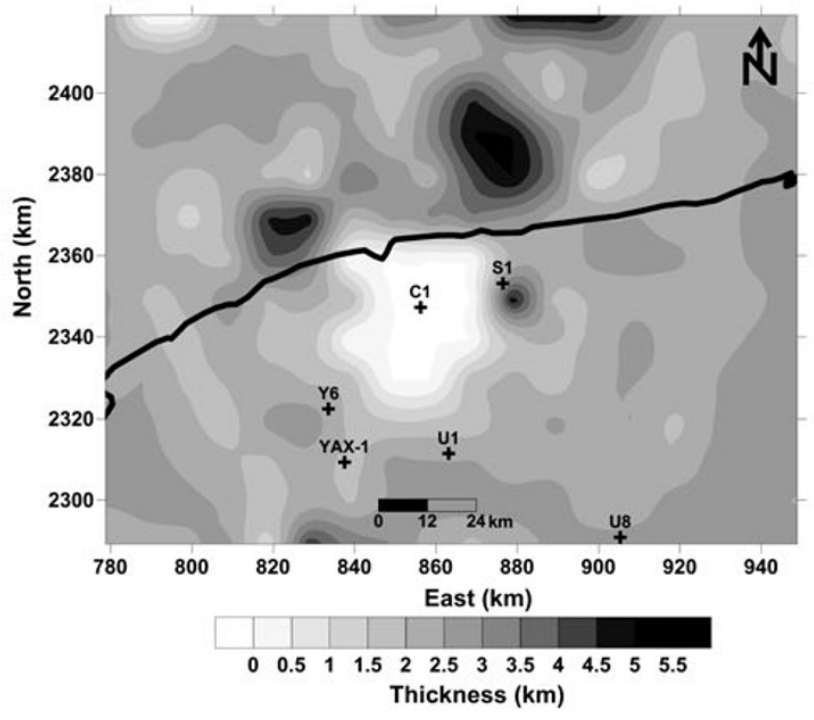

(b)

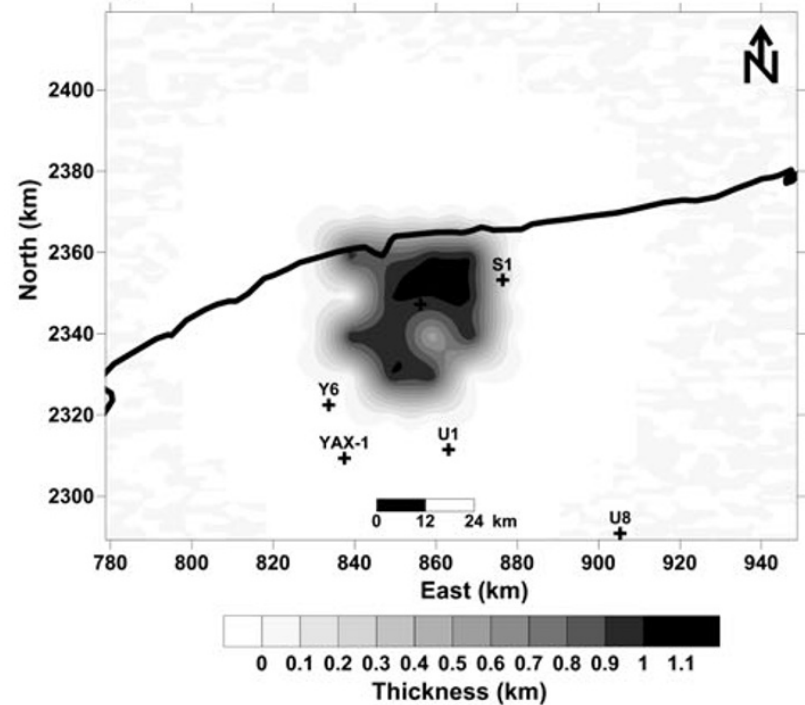

(d)

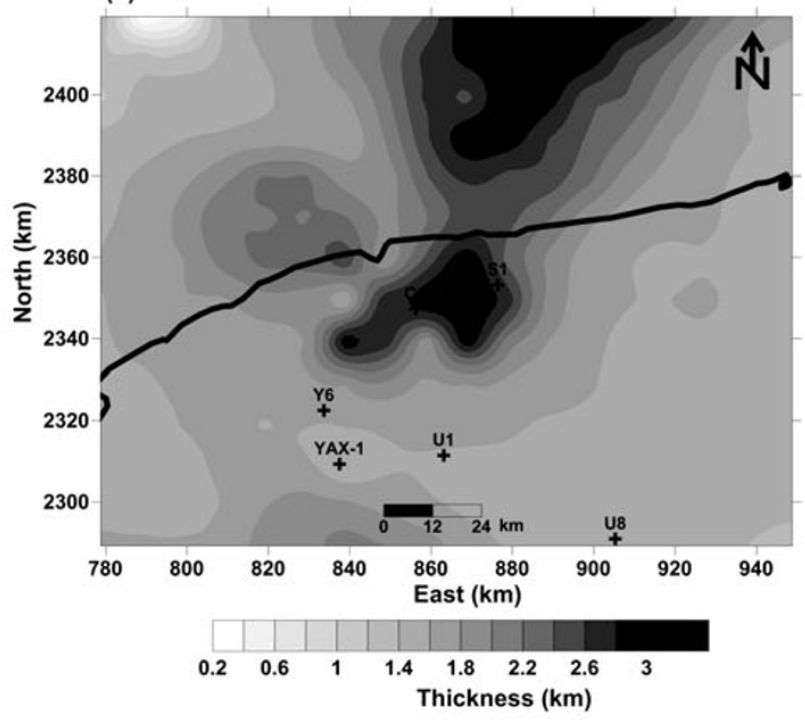

(e)

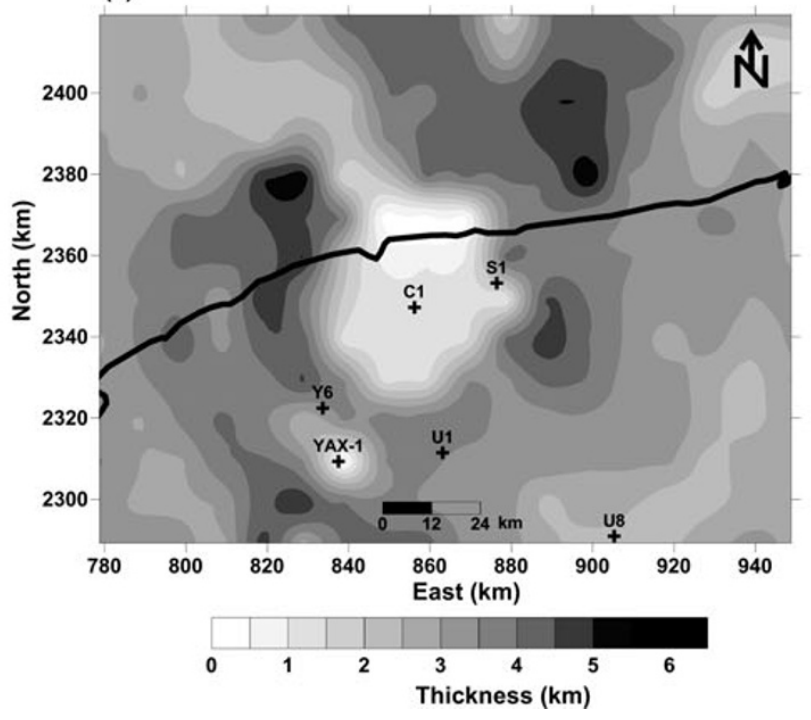

Fig. 8. Thickness of the rock groups: a) Breccias; b) Melt; c) Cretaceous carbonates; d) Upper crust; e) Filling the post-impact basin. 
units show normal faulting pointing to the center of the crater, having an irregular but circular symmetry. On top of Cretaceous is more obvious, describing a circular depression. Normal faults on Cretaceous (denser formation) are highly correlated with the rings obtained by the horizontal gradient of the gravity anomaly (ring-1, ring-2; $\sim 52$ $\mathrm{km}, \sim 77 \mathrm{~km}$ ). This depression does not conform to a sharp circle. The inversion model retrieves the ring morphology, confirming Chicxulub Crater has complex multiple rings at deep.

Cretaceous is absent at the center, meaning that a central collapse occurred. After the impact a rebound from the crust occurred and then a collapse. The remaining of this rebound is the central uplift (upper and lower crust composition) plotted in our cross-sections and the isometric graphs. Over this central uplift there is a layer of melt and over it a thin breccias layer. We kept constant the density for the upper and lower crust, but we believe that a mixing occurred between the crust and the upper layers, reducing the bulk density of the rebound. About the central uplift, our 3-D model locates the top depth of the melt at $\sim 1.1 \mathrm{~km}, \sim 2 \mathrm{~km}$ for the upper crust and $\sim 4 \mathrm{~km}$ for lower. If mixing with upper layers occurred, the top depth of the lower crust can be slightly shallower.

The central uplift produces a positive high on the gravity anomaly. This central high shows two peaks that are related to the features on top of the central uplift. The negative anomaly is justified by increasing the breccias thickness or increasing the top depth to the Cretaceous unit.

Acknowledgments. Marco Antonio Pérez Flores thanks to the Royal Society and Conacyt for their financial support for the sab- batical leave at UK. José Alberto Batista Rodriguez thanks to Conacyt for the Fellowship obtained to run this research at Mexico. Partial support provided by Papiit IN-101112.

\section{Appendix A.}

In Fig. A.1 is shown the error bars for every surface of the 3D model. These bars were calculated by modifying the initial model in 5\% for the every density contrast. Figure A.1(a) shows the error on the Tertiary surface when moving the initial densities in 5\%. A $5 \%$ perturbation on Tertiary density contrast, will produce a depth perturbation on every free surface. We added the all the perturbations for the bottom Tertiary surface and calculated the average for every single prisms. Same was done to the others free surface on the 3D model.

We only put the bars where error was larger than \pm 0.1 $\mathrm{km}$. Contours are every $0.1 \mathrm{~km}$, except melt with $0.01 \mathrm{~km}$ interval. Error bars were low for must of the surfaces, except for Tertiary at prisms (193, 194 and 173), where error is large considering that depth estimated was around $1.2 \mathrm{~km}$. This means that even data were homogeneous distributed all over the area, they did not have enough information about high frequencies of $1 \mathrm{~km}$ targets, and data in that small area were not able to constraints accurately the bottom Tertiary. Depths in this small area are not confident for bottom Tertiary only.

Error bars for bottom suevitic breccias and Cretaceous are low and expressed all over the area except where the central uplift (prisms; 149, 150, 151, 169, 170, 171, 189, 190, 191) is located (Fig. A.1(c); Fig. A.1(e)). Contrary, error bars for bottom melt is located just where central uplift is located (Fig. A.1(d)). Depth correlations between bottom
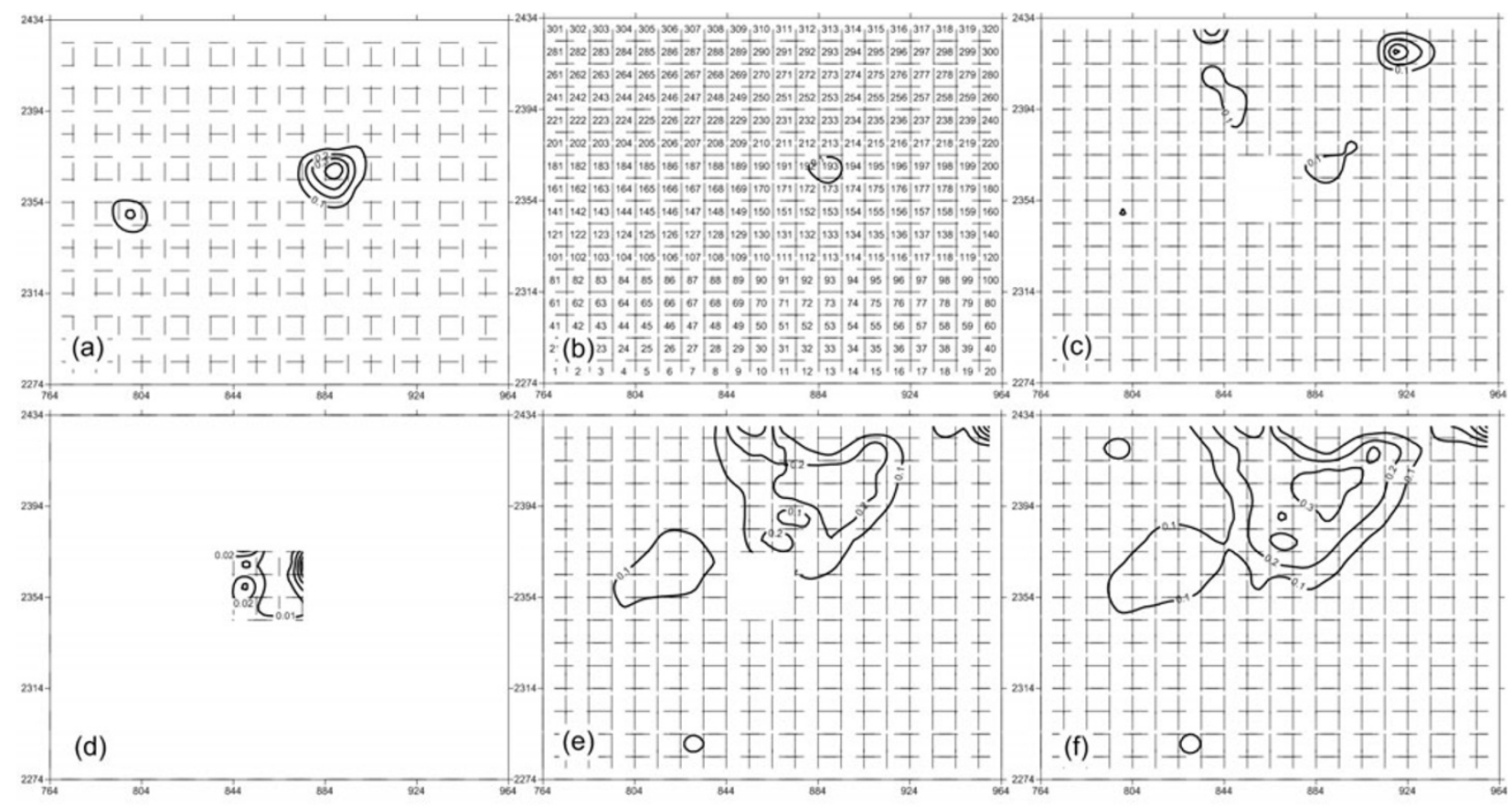

Fig. A.1. Error bars for the bottom depth estimation of every layer. Those were obtained by perturbing density contrast by 5\%. Procedure consisted in perturbing a single density at the time and storing separately the depth perturbation for every layer. After perturbing all density contrasts, e.g. we added all depth perturbations for Tertiary and doing a depth average for every prism. Contours are every $0.1 \mathrm{~km}$, except bottom melt with $0.01 \mathrm{~km}$ interval. 
Cretaceous and bottom upper crust is high, even with the error bars. But maximum is $\pm 0.3 \mathrm{~km}$ in depths larger than $10 \mathrm{~km}$.

\section{References}

Campos-Enríquez, J. O., F. J. Chávez-García, H. Cruz, J. G. Acosta-Chang, T. Matsui, J. A. Arzate, M. J. Unsworth, and J. Ramos-López, Shallow crustal of Chicxulub impact imaged with seismic, gravity and magnetotelluric data: Inferences about the central uplift, Geophys. J. Int., 157, 515-525, 2004.

Christeson, G., Y. Nakamura, R. T. Buffler, J. Morgan, and M. Warner, Deep crustal structure of the Chicxulub impact crater, J. Geophys. Res., 106, 21751-21769, 2001.

Collins, G. S., J. Morgan, P. Barton, G. Christeson, S. Gulick, J. UrrutiaFucugauchi, M. Warner, and K. Wünnemann, Dynamic modeling suggests asymmetries in the Chicxulub Crater are caused by target heterogeneity, Earth Planet. Sci. Lett., 270, 221-230, 2008.

Elbra, T. and J. J. Pesonen, Physical properties of the Yaxcopoil-1 deep drill core, Chicxulub impact structure, Mexico, Meteorit. Planet. Sci., 46(11), 1640-1652. doi:10.1111/j.1945-5100.2011.01253.x, 2011.

Gallardo-Delgado, A., M. A. Pérez-Flores, and E. Gómez-Treviño, Refinement of three-dimensional multi-layer models of basins by inversion of gravity and magnetic data, Tectonophysics, 397, 37-54, 2005.

Gill, P. E., W. Murray, M. A. Saunders, and M. H. Wright, User's guide for NPSOL (version 4.0): A Fortran package for nonlinear programming, Technical Report SOL 86-2 Department of Operations Research, Stanford University, 1986.

Gulick, S. P. S., P. J. Barton, G. L. Christeson, J. V. Morgan, M. McDonald, K. Mendoza-Cervantes, Z. F. Pearson, A. Surendra, J. UrrutiaFucugauchi, P. M. Vermeesch, and M. R. Warner, Importance of preimpact crustal structure for the asymmetry of the Chicxulub impact crater, Nat. Geosci., 1, 131-135, 2008.

Hildebrand, A. R., G. T. Penfield, D. A. Kring, M. Pilkington, A. CamargoZanoguera, S. B. Jacobsen, and W. V. Boynton, Chicxulub Crater: A possible Cretaceous/Tertiary boundary impact crater on the Yucatan Peninsula, Mexico, Geology, 19, 867-871, 1991.

Hildebrand, A. R., M. Pilkington, C. Ortiz-Aleman, R. E. Chavez, J. Urrutia-Fucugauchi, M. Connors, E. Graniel-Castro, and D. Niehaus, Mapping Chicxulub Crater structure with gravity and seismic reflection data, in Meteorites: Flux With Time and Impact Effects, edited by M. M. Graddy, R. Hutchinson, G. J. H. McCall, and D. A. Rotherby, Geological Society, London, Special Publications, 140, 155-176, 1998.

Mayr, S. I., A. Wittmann, H. Burkhardt, Y. Popov, R. Romushkevich, I. Bayuk, P. Heidinger, and H. Wilhelm, Integrated interpretation of physical properties of rocks of the borehole Yaxcopoil-1 (Chicxulub impact structure), J. Geophys. Res., 113, B07201, doi:10.1029/2007JB005420, 2008.

Melosh, H. J., Impact Cratering: A Geologic Process, pp. 245, Oxford University Press, New York, 1989.

Morgan, J., M. Warner, and Chicxulub Working Group, Size and morphology of the Chicxulub impact crater, Nature, 390, 472-476, 1997.

Morgan, J. and M. Warner, Morphology of the Chicxulub impact: Peakring crater or multi-ring basin, in Large Meteorite Impacts and Planetary Evolution, 339, 281-290, edited by B. Dressler, and V. Sharpton, Spec. Pap. Geol. Soc. Am. Boulder, CO, 1999.

Morgan, J., M. Warner, and Chicxulub Working Group, The Chicxulub seismic experiment: Crater morphology, in Impact Cratering and Plan- etary Evolution II, edited by B. O. Dressler and V. L. Sharpton, Geological Society of America Special Paper 339, 1999.

Morgan, J., M. Warner, G. S. Collins, H. J. Melosh, and G. L. Christeson, Peak-ring formation in large impact craters: Geophysical constraints from Chicxulub, Earth Planet. Sci. Lett., 5660, 1-8, 2000.

Ortiz-Alemán, C. and J. Urrutia-Fucugauchi, Aeromagnetic anomaly modeling of central zone structure and magnetic sources in the Chicxulub Crater, Phys. Earth Planet. Inter., 179, 127-138, 2010.

Pilkington, M. and A. R. Hildebrand, Three-dimensional magnetic imaging of the Chicxulub Crater, J. Geophys. Res., 105, 23479-23491, 2000.

Pilkington, M., A. R. Hildebrand, and C. Ortiz-Aleman, Gravity and magnetic field modeling and structure of the Chicxulub Crater, Mexico, $J$. Geophys. Res., 99(E6), 147-162, 1994.

Rebolledo-Vieyra, M., J. Urrutia-Fucugauchi, L. Marin, A. Trejo, V. Sharpton, and M. Soler, UNAM scientific shallow-drilling program of the Chicxulub impact crater, Int. Geol. Rev., 42, 928-940, 2000.

Salguero-Hernández, E., J. Urrutia-Fucugauchi, and L. Ramírez-Cruz, Fracturing and deformation in the Chicxulub crater-Complex trace analysis of instantaneous seismic attributes, Revista Mexicana de Ciencias Geológicas, 27, 175-184, 2010.

Schulte, P., L. Alegret, and Chicxulub Working Group, The Chicxulub asteroid impact and mass extinction at the Cretaceous-Paleogene boundary, Science, 327, 1214-1218, 2010.

Sharpton, V. L., G. Dalrymple, L. Marin, G. Ryder, B. Schuraytz, and J. Urrutia-Fucugauchi, New links between the Chicxulub impact structure and the Cretaceous/Tertiary boundary, Nature, 359, 819-821, 1992.

Sharpton, V. L., K. Burke, A. Camargo, S. A. Hall, S. Lee, L. Marin, G. Suarez, J. M. Quezada, P. D. Spudis, and J. Urrutia-Fucugauchi, Chicxulub multiring impact basin: Size and other characteristics derived from gravity analysis, Science, 261, 1564-1567, 1993.

Sharpton, V. L., L. E. Marin, J. L. Carney, S. Lee, G. Ryder, B. C. Schuraytz, P. Sikora, and P. D. Spudis, Model of the Chicxulub impact basin based on evaluation of geophysical data, well logs, and drill core samples, in The Cretaceous-Paleogene Event and other Catastrophes in Earth History, edited by G. Ryder, D. Fastovsky, and S. Gartner, Geol. Soc. Am. Spec. Paper, 307, 55-74, 1996.

Urrutia-Fucugauchi, J., L. Marin, and A. Trejo-Garcia, UNAM scientific drilling program of Chicxulub impact structure: Evidence of a $300-\mathrm{km}$ crater diameter, Geophys. Res. Lett., 23, 1565-1568, 1996.

Urrutia-Fucugauchi, J., J. Morgan, D. Stoeffler, and P. Claeys, The Chicxulub Scientific Drilling Project, Meteor. Planet. Sci., 39, 787-790, 2004. Urrutia-Fucugauchi, J., J. M. Chavez-Aguirre, L. Pérez-Cruz, and J. L. De la Rosa, Impact ejecta and carbonate sequence in the eastern sector of Chicxulub Crater, Comptes Rendus Geosciences, 340(12), 801-810, 2008.

Urrutia-Fucugauchi, J., A. Camargo-Zanoguera, L. Pérez-Cruz, and G. Pérez-Cruz, The Chicxulub multi-ring impact crater, Yucatan carbonate platform, Gulf of Mexico, Geofísica Internacional, 50(1), 99-127, 2011.

Vermeesch, P. M. and J. V. Morgan, Chicxulub central crater structure: Initial results from physical property measurements and combined velocity and gravity modeling, Meteor. Planet. Sci., 39, 1019-1034, 2004.

Vermeesch, P. M. and J. V. Morgan, Structural uplift beneath the Chicxulub impact structure, J. Geophys. Res., 113, B07103, 2008.

J. A. Batista-Rodríguez (e-mail: josebatista@uadec.edu.mx), M. A. Pérez-Flores, and J. Urrutia-Fucugauchi 